\title{
Cellular and Axonal Constituents of Neocortical Molecular Layer Heterotopia
}

\author{
Raddy L. Ramos ${ }^{a}$ Nga Yan Siu ${ }^{a}$ William J. Brunken ${ }^{c, d}$ Kathleen T. Yee ${ }^{g}$ \\ Lisa A. Gabel ${ }^{e, f}$ Sarah E. Van Dine ${ }^{a}$ Blair J. Hoplight ${ }^{b}$ \\ ${ }^{a}$ Department of Biomedical Sciences, New York Institute of Technology College of Osteopathic Medicine, and \\ ${ }^{b}$ Department of Behavioral Sciences, New York Institute of Technology, Old Westbury, N.Y., Departments of \\ 'Ophthalmology and d Cell Biology, State University of New York, Downstate Medical Center, Brooklyn, N.Y.,

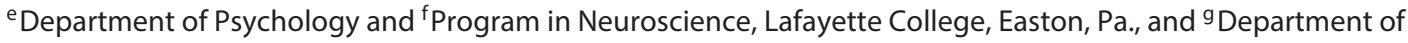 \\ Neurobiology and Anatomical Sciences, University of Mississippi Medical Center, Jackson, Miss., USA
}

\section{Key Words}

Neocortex $\cdot$ Malformation $\cdot$ Heterotopia $\cdot$ C57BL/6 mice

\begin{abstract}
Human neocortical molecular layer heterotopia consist of aggregations of hundreds of neurons and glia in the molecular layer (layer I) and are indicative of neuronal migration defect. Despite having been associated with dyslexia, epilepsy, cobblestone lissencephaly, polymicrogyria, and Fukuyama muscular dystrophy, a complete understanding of the cellular and axonal constituents of molecular layer heterotopia is lacking. Using a mouse model, we identify diverse excitatory and inhibitory neurons as well as glia in heterotopia based on molecular profiles. Using immunocytochemistry, we identify diverse afferents in heterotopia from subcortical neuromodulatory centers. Finally, we document intracortical projections to/from heterotopia. These data are relevant toward understanding how heterotopia affect brain function in diverse neurodevelopmental disorders.
\end{abstract}

(c) 2014 S. Karger AG, Basel

\section{KARGER}

(C) 2014 S. Karger AG, Base

0378-5866/14/0366-0477\$39.50/0

E-Mail karger@karger.com

www.karger.com/dne

\section{Introduction}

Dyslexia, epilepsy, cobblestone lissencephaly, polymicrogyria, and Fukuyama muscular dystrophy are very different neurodevelopmental disorders with highly dissimilar clinical manifestations. These diverse disorders surprisingly share one important neuroanatomical phenotype in common. Specifically, postmortem analyses of individuals affected by these disorders have revealed the presence of neocortical heterotopia consisting of aggregations of hundreds of neurons and glia in the molecular layer (layer I) that are indicative of neuronal migration defect [1-8]. Despite the potential clinical importance of understanding how heterotopia affect neocortical function in such disparate disorders, much remains to be revealed regarding the anatomy, physiology and etiology of heterotopia.

Spontaneous neocortical molecular layer heterotopia $(\mathrm{MLH})$ are present in several inbred mice $[9,10]$, including C57BL/6 mice [11-13]. MLH have also been observed in several knockout (KO) mice [14-23]. MLH in mice are indistinguishable from heterotopia observed in humans. Consistent with a model of altered brain function associated with MLH, mice with heterotopia have impaired 
learning of spatial and nonspatial memory tasks [24-28]. Mice with MLH also exhibit sensory processing deficits demonstrated by both behavioral measures in sensory discrimination tasks as well as with sensory-evoked potential recording [29-32]. Thus, findings in mice with MLH mimic the cognitive defects seen in humans with MLH. Furthermore, we have shown that mice with MLH also have lower seizure thresholds and shorter latency to seizures following chemi-convulsant treatment $[33,34]$, which mimic the brain excitability changes observed in epileptic humans with MLH. Thus, behavioral changes in mice with MLH closely resemble those observed in humans with MLH, demonstrating the utility of mice as a model of human MLH.

In the present report, we describe the cellular axonal anatomy of MLH in mice. We document the presence of astrocytes, oligodendrocytes and microglia in heterotopia. Furthermore, we identify the presence of serotonergic, cholinergic, catecholaminergic, and glutamatergic axons in heterotopia. These data are relevant toward an understanding of the mechanisms of neuronal migration and axonal targeting during normal and abnormal neocortical development.

\section{Materials and Methods}

We used C57BL6/J (stock No. 000664) and Thy1-yellow fluorescent protein mice (Thy1-YFP; H line; stock No. 003782 [35]) bred in academic vivaria from founders obtained from The Jackson Laboratory, as previously described $[36,37]$. Laminin $\beta 2 / \gamma^{3}$ double-KO mice were also examined, as well as laminin $\beta 2 / \gamma 3$ double-KO mice crossed with $\mathrm{Cx} 3 \mathrm{Cr} 1 / \mathrm{eGFP}$ transgenic mice, as previously described [14]. The mice were housed in temperature-controlled facilities maintained between 20 and $22.5^{\circ} \mathrm{C}$, with 12-hour light/dark cycles, in standard plastic cages $(11.75 \times 7.5 \times 5$ inches $)$ with no more than 5 mice per cage, and with food and water available ad libitum. Mice of either sex aged between 14 and 90 days were used, since by 7 days of age all neocortical neuronal migration has ended. As previously described $[13,36]$, breeding schemes at New York Institute of Technology were mixed and included both sibling and nonsibling matings. All measures were taken to minimize pain or discomfort in the mice and experiments were carried out in accordance with the National Institute of Health Guide for the Care and Use of Laboratory Animals (NIH publication No. 8023). All procedures were approved by the Institutional Animal Care and Use Committee at the New York Institute of Technology.

We followed histological methods identical to those described previously for mice $[12,36,38]$. Following perfusion and fixation ( $0.9 \%$ saline followed by $4 \%$ paraformaldehyde in $0.1 \mathrm{M}$ phosphate buffer), brains were cryopreserved in a $30 \%$ sucrose solution and then sectioned on a cryostat $(40 \mu \mathrm{m})$ and collected in $0.1 \mathrm{M}$ PBS. Unstained sections were first screened with a dissection microscope and oblique illumination. Heterotopia and associated myelinated bundles are visible with this method [13]. Once heteroto- pia were identified, sections were further processed for histochemistry or immunocytochemistry. Sections from 2-4 different brains containing heterotopia were examined for each stain described in the present report.

Immunocytochemistry was used to reveal the presence of different axonal phenotypes in heterotopia using methods previously described $[12,38]$. Briefly, free-floating sections were collected into different wells and washed with PBS (3 times). The sections were permeabilized and blocked in 5\% normal goat serum and $0.2 \%$ Triton $\mathrm{X}-100$ for $1 \mathrm{~h}$. They were then incubated in primary antibodies with $0.1 \%$ Triton $\mathrm{X}-100$ and $2.5 \%$ normal goat serum in PBS at $4{ }^{\circ} \mathrm{C}$ overnight. In the present study the following primary antibodies were used, as previously described [38]: serotonin transporter (5-HTT; 1:1,000; ImmunoStar, Hudson, Wisc., USA), tyrosine hydroxylase (TH; 1:1,000; Millipore, Billerica, Mass., USA), oligodendrocyte transcription factor 2 (Olig2; 1:1,000; Millipore), choline acetyltransferase (ChAT; 1:1,000; Millipore), glial fibrillary acidic protein (GFAP; 1:1,000; Sigma, St. Louis, Mo., USA) and ionized calcium-binding adapter molecule 1 (Iba1; 1:1,000; Wako, Richmond, Va., USA).

Following incubation in primary antibodies for use with brightfield microscopy, the sections were rinsed in PBS and then incubated in biotinylated secondary antibodies (goat anti-mouse, goat anti-rabbit; 1:200, Vector Labs, Burlingame, Calif., USA) for $2 \mathrm{~h}$ at room temperature. They were then rinsed in PBS and incubated for $1 \mathrm{~h}$ in an avidin-horseradish peroxidase mixture. Again, the sections were rinsed in PBS and then reacted with $0.05 \%$ diaminobenzidine $/ 0.0015 \% \mathrm{H}_{2} \mathrm{O}_{2}$. For epifluorescence imaging, Alexa 488or 568-conjugated secondary antibodies were used (1:200; Life Technologies, Grand Island, N.Y., USA). Fluorescent counterstaining was performed with DAPI, propidium iodide or SYTOX Green (Life Technologies).

Stained sections were collected onto gelatin-coated slides and coverslipped. Digital photomicrographs were taken at varying magnification on an Olympus BX41 or Leica SP5 confocal microscope. Figures were prepared in Adobe Photoshop.

\section{Virtual Data Collection from the Allen Brain Atlas}

The Allen Brain Atlas (ABA; www.brain-map.org) was used to document malformations in $\mathrm{C} 57 \mathrm{BL} / 6 \mathrm{~J}$ mice according to methods previously described $[12,36,38,39]$. The $\mathrm{ABA}$ is a public database containing photomicrographs of brains from C57BL/6J mice (obtained from Jackson Laboratories) processed for in situ hybridization according to methods described by Lein et al. [40]. Serial coronal and/or sagittal cryostat sections are found in the ABA (25$\mu \mathrm{m}$ thickness) for each of over 20,000 genes.

We used the search features of the ABA to generate lists of genes/histological cases from which we searched for heterotopia. For example, the ABA has preset lists of genes/cases that show differential expression in particular regions of interest (including distinct layers of the neocortex) that are easily accessible at the 'Gene Search' homepage of the ABA (http://mouse.brain-map. org/search/index). We directly examined the cases found in the following preset lists under the 'Browse by Differential Expression' tab: cerebral cortex, layer 2-3; cerebral cortex, layer 4; cerebral cortex, layer 5 , and cerebral cortex, layer $6 a$. For a search of genes in layer VIb neurons, we used the list found in the 'Fine Structure Search' tab for the search term 'layer 6B, isocortex' (http://mouse. brain-map.org/search/show?page_num $=0$ \&page_size $=20 \&$ no_ paging=false\&search_term $=16 \&$ search_type $=$ fine_structure $). W e$ 
also used published articles for layer-specific genes to include in our search [41-45]. For genes differentially expressed in different glial cell types, we used the list found in the study by Lein et al. [40]. A list of genes differentially expressed in GABAergic neurons was created based on the interneuron subtypes described by DeFelipe et al. [46].

From among thousands of images examined, a very small number of cases were archived that contained one of the following: (1) largely-unequivocal differential expression in a given neocortical layer or (2) expression in a given cell type. All of the cases meeting these criteria are either displayed in part of a figure or mentioned in the text with the corresponding $\mathrm{ABA}$ experiment number listed. The raw ABA data for each of the cases described/illustrated can be easily accessed by typing the experiment number on the ABA website search tab. Cases that did not have heterotopia were not recorded because we cannot be certain that heterotopia were not present, since not every section is stained and imaged for a given gene. In addition, we did not record cases where heterotopia were present but the staining pattern was either uninformative about cell type or where the expression pattern was not layer specific.

Having identified genes with cell type- or layer-specific expression, we examined additional material of the ABA, including the Developing Mouse Brain database (http://developingmouse.brain-map.org), which contains data from embryonic (E) and postnatal (P) C57BL/6J mice. Data from mice aged 18 and 24 months $(\mathrm{M})$ are also present in this database. The Sleep (http://sleep.alleninstitute.org), Mouse Connectivity (http:// connectivity.brain-map.org/) and Mouse Diversity (http:// mousediversity.alleninstitute.org) databases found in the ABA were also examined in the present report. According to the technical white paper regarding the in situ hybridization and tissue processing from the ABA (http://help.brain-map.org/download/attachments/2818169/ABADataProductionProcesses.pdf? version $=1 \&$ modificationDate $=1319477154403$ ), each brain was used in the production of approximately $6-8$ cases/tissue series, which were used to hybridize for multiple genes or replicates of similar genes.

Photomicrographs containing the section with the largest extent of heterotopia were digitally archived. Representative photomicrographs taken from the ABA were imported into Photoshop for the preparation of figures.

Virtual Data Collection from the Mouse Brain Architecture Project and Mouse Connectome Project

Our laboratory has established that internet databases like the ABA [12] and the Mouse Brain Library [13] that feature C57BL/6 mouse brain histology can be used to determine the cell types present in MLH. With this in mind, we performed detailed searches through databases with histological data from neuronal tracer studies performed in C57BL/6 mice, including the following: (1) the Mouse Connectome Project (MCP, mouseconnectome.org), (2) the Mouse Brain Architecture Project (MBAP, brainarchitecture.org/mouse) and (3) the Mouse Connectivity database (connectivity.brain-map.org) of the ABA. In each of these databases, several dozen digital micrographs are available for each brain following unilateral neuronal tracer injection. Thus, thousands of digital micrographs from these databases were examined for the presence of MLH. Cases with MLH and labeled axons or neurons from anterograde and retrograde (respectively) tracing experiments were digitally archived.

Cells and Circuits of Neocortical

Heterotopia

\section{Results}

\section{MLH Contain Glutamatergic Neurons from All}

\section{Neocortical Lamina}

With the continued addition of new data to the ABA, we were able to identify numerous neuronal classes in heterotopia not previously described. For example, as shown in figure 1, neurons expressing reprimo (Rprm; P56; ABA 78525701; fig. 1a, b), protein phosphatase 1, regulatory (inhibitor) subunit 1B (Ppp1r1b; P4; ABA 100055033; fig. 1c), and connective tissue growth factor (Ctgf; 18M; ABA 100098244; fig. 1d) were observed in MLH. Ppp1r1bexpressing neurons were not only found in heterotopia but also scattered throughout a number of other lamina. Given that the normal laminar profile of neurons expressing these genes is exclusive to layer VI, these data are indicative of defective migration among a limited number of glutamatergic neurons destined for layer VI. Furthermore, because cohorts of newly generated neurons migrate radially past earlier-born neurons during corticogenesis [47-49], these results indicate that even the earliest-born neocortical neurons are present in MLH.

ABA searches of tissue hybridized for genes found exclusively in layer $\mathrm{V}$ also indicated the presence of layer $\mathrm{V}$ neurons in MLH. For example, as shown in figure 1, we also observed neurons in MLH that express ets variant gene 1 (Etv1; P14; ABA 100026968; fig. 1e), fez-family zinc-finger 2 (Fezf2; P28; ABA 100022558; fig. 1f) and Ctip2 (also known as Bcl11b; P4; ABA 100055034; data not shown). In light of the fact that Fezf2-, Ctip2- and Etv1-expressing cells are known to send projections to the spinal cord $[41,42,45]$, these data suggest that MLH contain neurons with subcortical projections.

Based on the above observations and our previous results that nearly all substrains of C57BL/6 mice have MLH [13], we predicted that Thyl-YFP transgenic mice would also have MLH, since these mice have been backcrossed onto a C57BL/6 background [35]. As described previously $[35,50]$, YFP expression in the neocortex of these mice is specific to thick-tufted layer $\mathrm{V}$ neurons with corticospinal projections. Not surprisingly, following examination of primary histological material generated in our laboratory, we observed MLH in these transgenic mice (with a prevalence of about 10\%) and identified YFP-expressing cells in $100 \%$ of heterotopia as well as scattered in superficial lamina immediately below MLH (fig. 1g, h). Together with data from the ABA described above, these data demonstrate that layer $\mathrm{V}$ neurons with subcortical projections are found in MLH and that transgenic mice backcrossed onto a C57BL/6 background can exhibit MLH. 

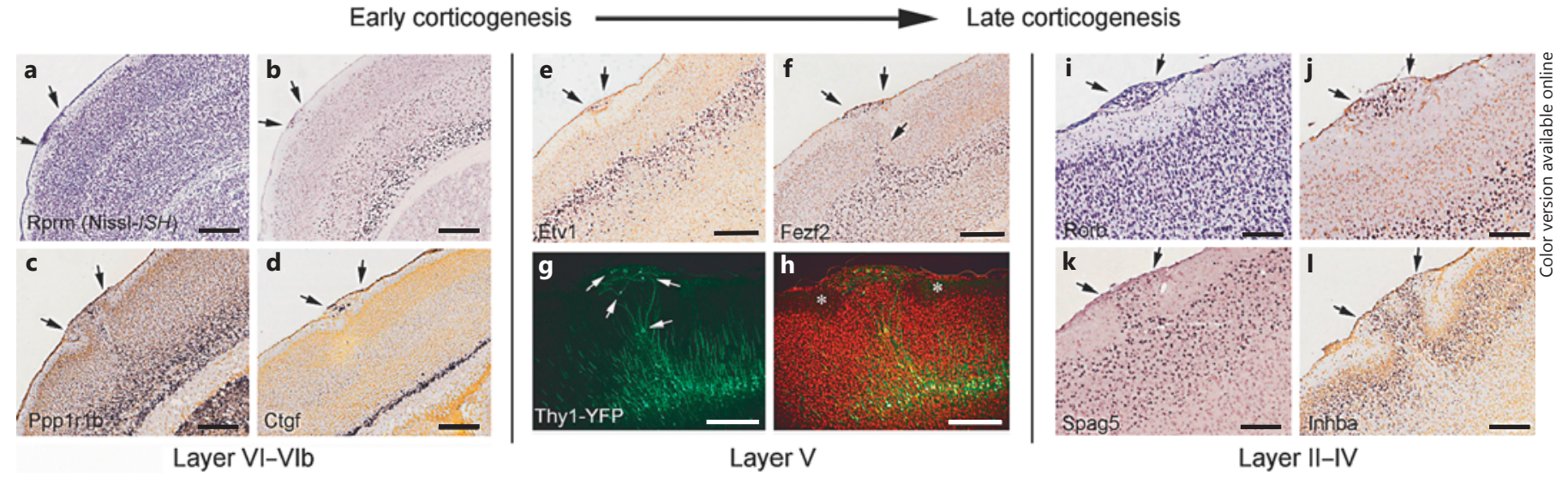

Fig. 1. Neurons born throughout corticogenesis are present in heterotopia. ISH = In situ hybridization. a-d Neurons belonging in layer VI are present in MLH. The Nissl-stained section in $\mathbf{a}$ is adjacent to the section shown in $\mathbf{b}$. e-h Neurons belonging in layer $\mathrm{V}$ are present in MLH. Propidium iodide counterstaining is shown in $\mathbf{h}$ and is the same section shown in $\mathbf{g}$. $\mathbf{i}, \mathbf{j}$ Neurons belonging in

layer VI are present in MLH. The Nissl-stained section in $\mathbf{i}$ is adjacent to the section shown in $\mathbf{j}$. $\mathbf{k}$, I Neurons belonging in layer II-III are present in MLH. Arrows in $\mathbf{a}-\mathbf{I}$ point to heterotopia. Data in $\mathbf{a}-\mathbf{f}$ and $\mathbf{i}-\mathbf{I}$ are from the ABA and all are from C57BL/6J mice. Data in $\mathbf{g}$ and $\mathbf{h}$ (Thy1-YFP tissue) are from primary histological samples from our laboratory. Scale bars: a-f, $\mathbf{i}-\mathbf{I}=421 \mu \mathrm{m} ; \mathbf{g}, \mathbf{h}=400 \mu \mathrm{m}$.

Neurons expressing RAR-related orphan receptor- $\beta$ (Rorb; P28; ABA 100039966; fig. 1i, j) were found in MLH as well as neurons expressing sperm-associated antigen 5 (Spag5; P56; ABA 72081516; fig. 1k) and inhibin- $\beta$-A (Inhba; P4; ABA 100056072; fig. 1l). We also observed Satb2-expressing neurons in heterotopia in P1 (ABA 100092087; data not shown) and P4 (ABA 100092539; data not shown) brains as well as Nlk-expressing neurons at P4 (ABA 100056055; data not shown). These observations demonstrate defective migration of neurons normally fated to be in layer II/III (e.g. Inhba, Spag5) and IV (e.g. Rorb), respectively. In light of previous reports that Inhba-expressing cells include neurons that make interhemispheric projections [44], these data suggest that MLH contain callosal neurons. Thus, MLH contain misplaced neurons that belong in all layers and therefore indicate a migration defect of neurons born during early (layer VI), mid (layers V, IV) and late (layers III, II) stages of corticogenesis.

\section{MLH Contain Diverse GABAergic Interneuron \\ Subtypes}

Different neocortical GABAergic neuron subtypes are generated from progenitor cells located in different spatial locations of the embryonic forebrain. For example, GABA neurons expressing parvalbumin (Pvalb) are born in the ventral division of the medial ganglionic eminence, while those expressing somatostatin (Sst) are born in the dorsal division [51]. In contrast, GABA neurons expressing vaso- active intestinal polypeptide (Vip) and calretinin (Calr) derive from progenitors located in the caudal ganglionic eminence [51]. Different subtypes of GABAergic interneurons also differ in morphological and electrophysiological features as well as their preferred synaptic targets [52]. For example, $P$ valb interneurons have multipolar morphology, preferentially synapse on the soma and proximal dendrites of pyramidal cells and are capable of very high-frequency action potential discharge [53]. In addition, Pvalb neurons form electrical and chemical synapses onto other Pvalbexpressing cells $[54,55]$ and form chemical synapses on the soma and proximal dendrites of Vip neurons [56]. Based on these functional and developmental characteristics of GABAergic neurons, identifying different subtypes in MLH has important implications for understanding the morphological and physiological phenotypes as well as the developmental origins of GABAergic cells in heterotopia.

Three major subgroups of interneurons account for nearly $100 \%$ of neocortical GABAergic neurons in the mouse brain and can be distinguished by the following molecular markers: Pvalb, Sst and the serotonin 3a receptor (5HT3aR [52]). ABA searches revealed that numerous GABAergic subtypes are indeed present in MLH, including neurons expressing glutamic acid decarboxylase 1 (Gad1; P28; ABA 100039955; fig. 2a, b), Vip (P4; ABA 100074480; fig. 2c), Pvalb (P28; ABA 100039969; fig. 2d), and 5HT3aR neurons (P56; ABA 74724760; fig. 2e). We also observed additional interneuron subclasses, including those expressing Tac1 (P28; ABA 100056865; fig. 2f), Erbb4 


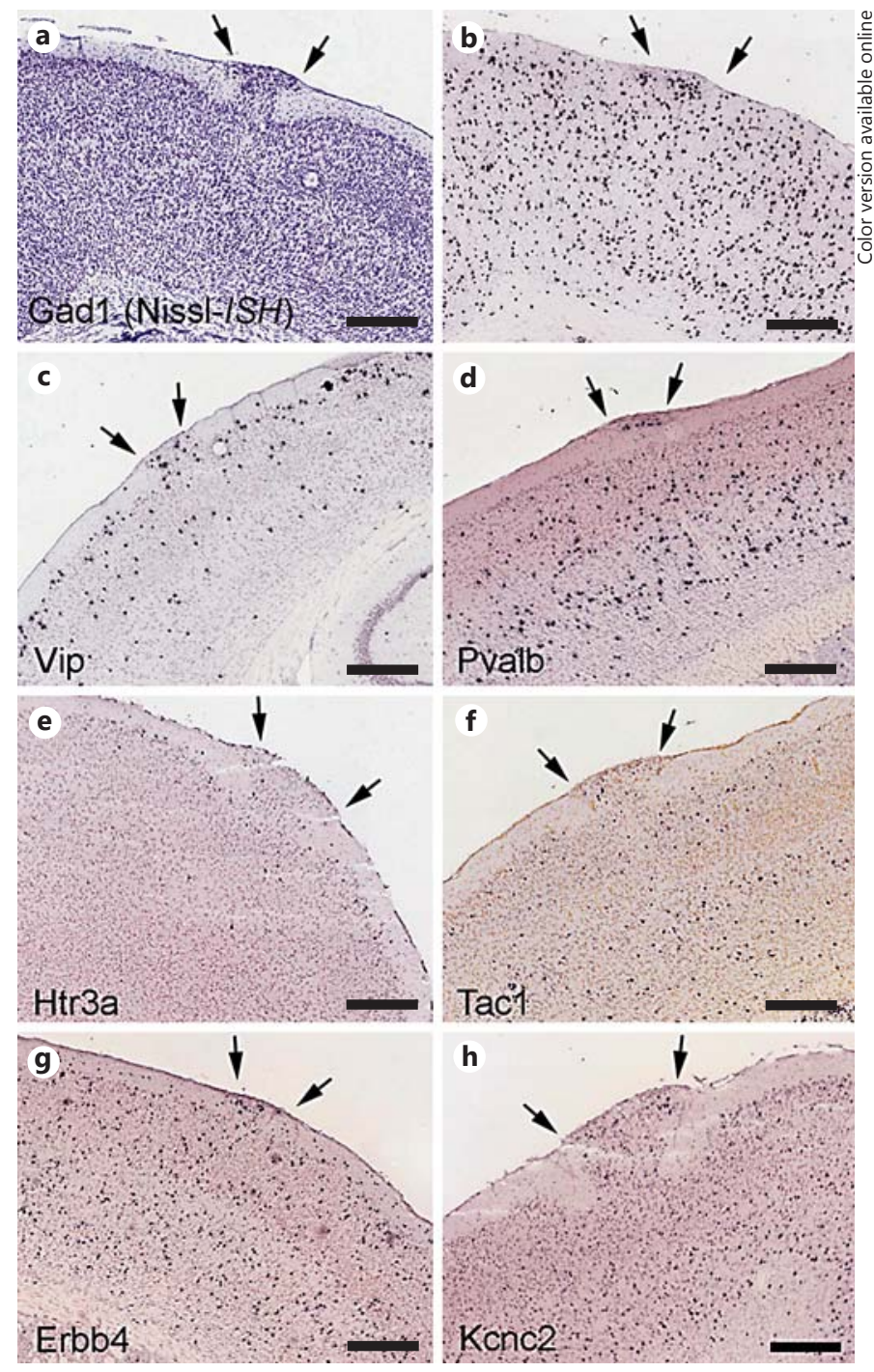

Fig. 2. Diverse GABAergic interneurons are present in heterotopia. ISH = In situ hybridization. $\mathbf{a}-\mathbf{h}$ In situ hybridization of GABAergic interneuron subtypes in heterotopia. The Nisslstained section in $\mathbf{a}$ is adjacent to the section shown in $\mathbf{b}$. Arrows in $\mathbf{a}-\mathbf{h}$ point to heterotopia. All data $(\mathbf{a}-\mathbf{h})$ are from the ABA and all are from C57BL/6J mice. Scale bars: $\mathbf{a}-\mathbf{h}=421 \mu \mathrm{m}$.

(P56; ABA 72472797; fig. 2g) and Kcnc2 (P56; ABA 73512364; fig. 2h). In addition, we identified Pdyn-expressing cells (P28; ABA 100042562; data not shown) in heterotopia, which were recently shown to be a large subpopulation of Sst interneurons [57]. These data indicate that many, if not all, subtypes of GABA neurons migrate into MLH in mice, including those born in the caudal (Vip) and medial (Pvalb) ganglionic eminences [51]. These data also suggest that somatic (Pvalb) and dendritic (Vip) GABAergic synapses are present in heterotopia [52].

Cells and Circuits of Neocortical

Heterotopia

\section{MLH Contain Diverse Glial Cell Types}

Three major subtypes of glial cells found in the neocortex include astrocytes, oligodendrocytes, and microglia. We searched the ABA for genes exclusively found in astrocytes and confirmed that astrocytes are present in MLH. As shown in figure 3a-c, we found that cells expressing Glast (P28; ABA 100083582), Gfap (P56; ABA 79160968) and $I d 3$ (P56; ABA 74724763) were in MLH and none of these expression profiles indicated increased numbers of astrocytes associated with heterotopia. Moreover, when we performed immunostaining against GFAP (data not shown) on sections of C57BL/6J brains with $\mathrm{MLH}$, we did not observe astrocytes with activated morphologies, indicating no reactive astrocytosis.

Myelinated axons have been previously identified in MLH $[12,13]$, indicating that oligodendrocytes are also present. Not surprisingly, we performed immunostaining against the oligodendrocyte-specific molecule Olig2 [5860 ] on sections of C57BL/6J brains with MLH and observed that oligodendrocytes are indeed present in MLH (data not shown). Moreover, as shown in figure $3 \mathrm{~d}-\mathrm{f}$, $\mathrm{ABA}$ searches for oligodendrocyte-specific genes revealed the presence of cells expressing $M b p$ (18M; ABA 100082169), Plp1 (P28; ABA 100039826) and Gpr37 (P28; ABA 100039821) in heterotopia.

In order to identify microglia in heterotopia, we performed immunostaining on sections of C57BL/6J brains with MLH against Iba1, a microglia-specific marker which is particularly useful in determining the activation of microglia via changes in staining intensity, soma size and shape, and ramification of processes $[61,62]$. Iba1expressing microglia were present in heterotopia but microglial morphology did not indicate an activated phenotype (data not shown). In order to confirm these results, we examined primary histological material in our laboratory of brains of laminin $\beta 2 / \gamma 3$ double-KO mice which develop numerous MLH throughout most of the neocortex [14]. Similar to our observations in C57BL/6J mice, we found that Ibal-expressing microglia were present in heterotopia in laminin $\beta 2 / \gamma 3$ double-KO mice (data not shown). Moreover, as shown in figure $3 \mathrm{~g}$, when laminin $\beta 2 / \gamma 3$ double-KO mice were crossed to reporter mice expressing enhanced GFP in microglia (Cx3Cr1/eGFP), numerous microglia were evident in heterotopia, though activated morphologies were not observed, suggesting that heterotopia are not associated with inflammatory or macrophagic responses. As shown in figure $3 \mathrm{~h}$ and $\mathrm{i}$, similar results were found following $\mathrm{ABA}$ searches for microglia-specific markers such as CD11b/Itgam (P14; ABA 100075158) and C1qa (18M; ABA 100082352). 

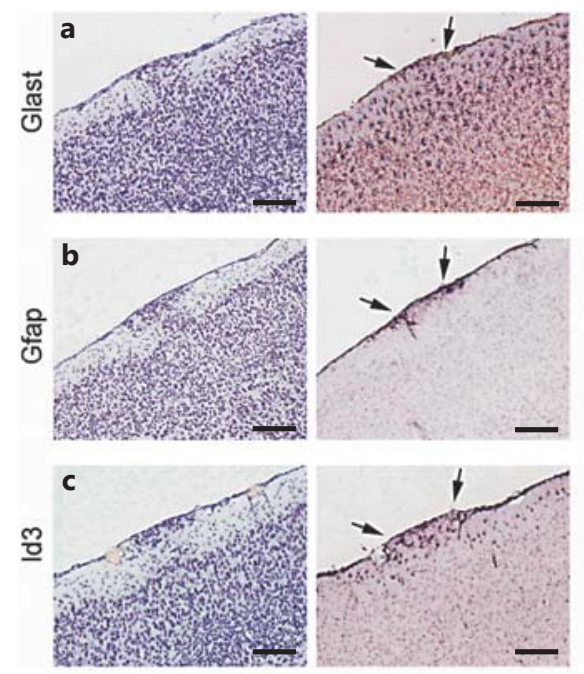

Astrocytes
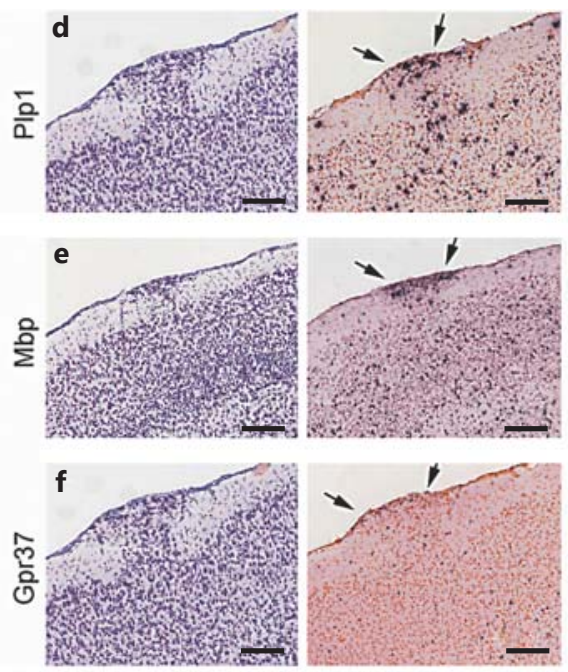

Oligodendrocytes
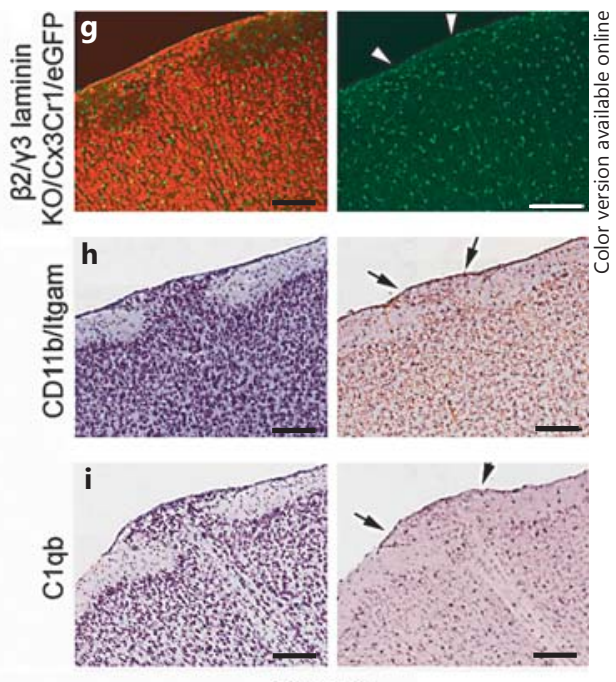

Microglia
Fig. 3. Diverse glial cell types are present in heterotopia. a-c Astrocytes are present in MLH. d-f Oligodendrocytes are present in MLH. g-i Microglia are present in MLH in laminin $\beta 2 / \gamma 3-\mathrm{Cx} 3 \mathrm{Cr} 1 /$ eGFP triple transgenic mice. Arrows in a-i point to heterotopia. Nissl-stained sections in left-side panels of $\mathbf{a}-\mathbf{f}, \mathbf{h}$ and $\mathbf{i}$ are adjacent to sections shown in right-side panels. Propidium iodide counter-

Taken together, these results indicate that all three glial cell types are present in MLH without apparent reactive astrocytes or activated microglia.

\section{MLH Contain Diverse Axons from Subcortical}

\section{Afferents}

Identifying the afferent and efferent projections of MLH has remained elusive due to the fact that only a fraction of mice exhibit heterotopia [12,13], and the location of MLH is not known a priori to microinjection of tracers. However, afferents from specific subcortical nuclei to MLH can be identified by immunostaining for specific neurotransmitter phenotypes, as we have previously described for projections to cerebellar malformations [38]. As shown in figure 4, following the examination of primary histological material generated in our laboratory, we identified a dense plexus of axons expressing the serotonin transporter (5HTT) in MLH in C57BL/6J mice. The density of labeled axons within heterotopia appeared largely similar to the density present in adjacent regions of the molecular layer. Moreover, 5HTT-labeled axons were not found to form bundles immediately below heterotopia (fig. 4e, f), as we have observed previously for myelinated axons $[12,13]$. These data indicate that serotonergic neurons project to neurons in heterotopia. staining shown in the left-side panel in $\mathbf{g}$ is the same section shown in the right-side panel. Data in $\mathbf{a}-\mathbf{f}, \mathbf{h}$ and $\mathbf{i}$ are from the ABA. Data in $\mathbf{g}$ are from primary histological samples from our laboratory. All data are from C57BL/6J mice except in $\mathbf{g - i}$. Scale bars: a, d, f, $\mathbf{h}, \mathbf{i}=209 \mu \mathrm{m} ; \mathbf{b}, \mathbf{e}=262 \mu \mathrm{m} ; \mathbf{c}=196 \mu \mathrm{m} ; \mathbf{g}=125 \mu \mathrm{m}$.

ChAT and TH immunostaining were also performed to determine whether cholinergic and catecholaminergic axons are in MLH, respectively. As shown in figures 5 and 6 (respectively), following the examination of primary histological material generated in our laboratory of C57BL/6J mouse brains with heterotopia, a dense plexus of ChAT- and TH-expressing axons was also observed in heterotopia. However, neither axon type was found to form bundles immediately below the heterotopia, as has been observed for myelinated axons $[12,13]$. ChAT-expressing interneurons were also found in heterotopia. These data indicate that diverse axonal afferents from several subcortical nuclei are present in MLH.

\section{MLH Contain Callosal Neurons, Callosal Axons and Local Intracortical Axons}

We identified the Mouse Connectivity database, MCP and MBAP as three online databases we could use to further examine the afferent and efferent projections to heterotopia in C57BL/6J mice. Results from detailed searches of the data on the MCP and MBAP are only reported here as these two databases have Nissl counterstaining which allowed us to unequivocally identify MLH. We did indeed identify cases with heterotopia in both the MCP and MBAP; however, only a small fraction of cases had anterograde or retrograde labeling. This is to be expected 
Fig. 4. Serotonergic axons project to heterotopia. a Low magnification of the propidium iodide-stained section with visible heterotopion (arrows). b, c High magnification of heterotopion shown in $\mathbf{a}$, revealing neurons (b) and a dense plexus of 5HTT immunoreactive axons (c). $\mathbf{d}$ Merged image of $\mathbf{b}$ and $\mathbf{c}$. Arrowheads in b and $\mathbf{c}$ point to pial surface. e, $\mathbf{f}$ High magnification of the region shown in a by arrowheads, indicating that 5HTT fibers are not part of the axon bundle associated with MLH. All data (a-f) are from primary histological samples from our laboratory and all are from C57BL/6J mice. Scale bars: $\mathbf{a}=$ $220 \mu \mathrm{m} ; \mathbf{b}-\mathbf{f}=35.5 \mu \mathrm{m}$.
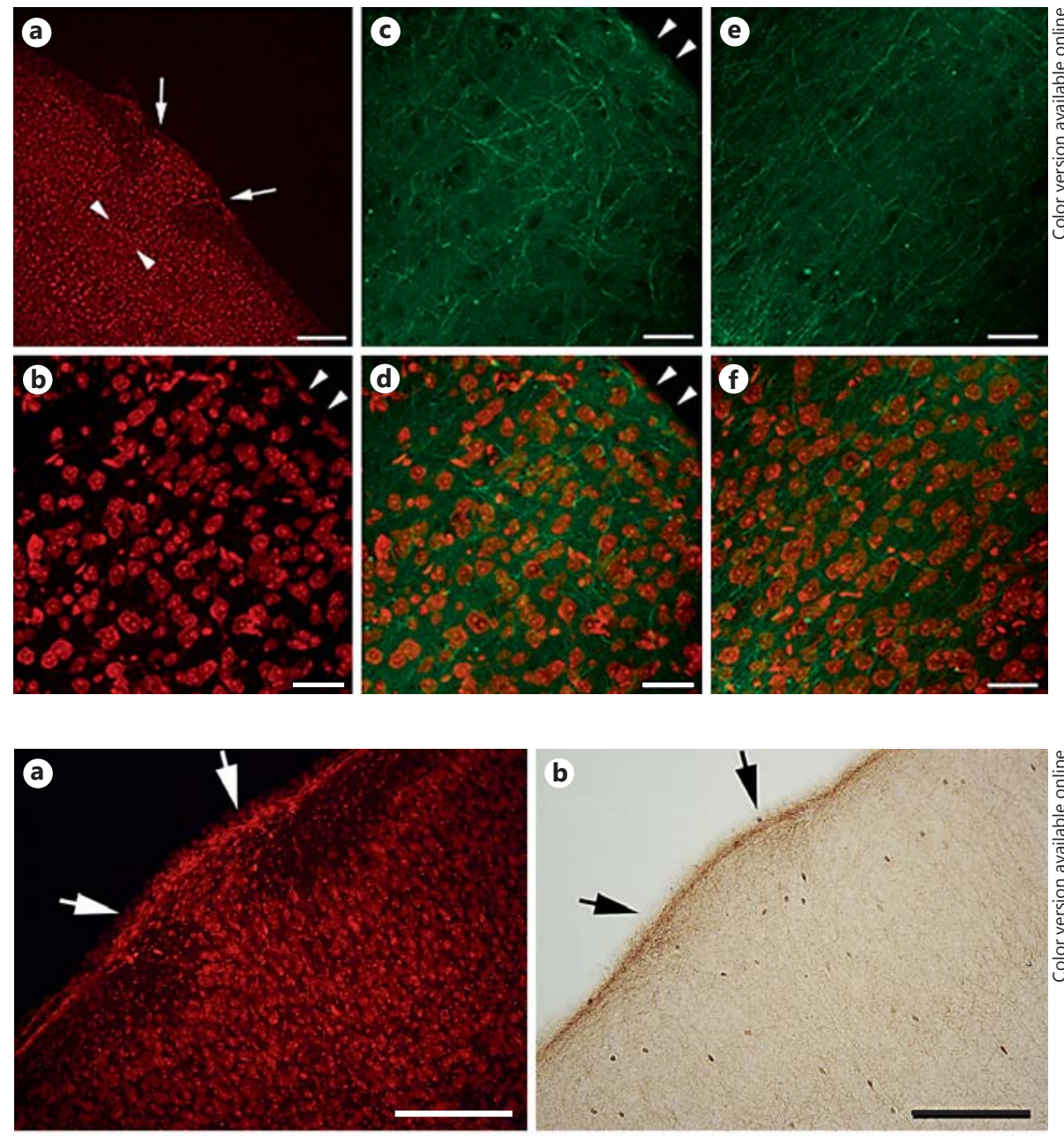

Fig. 5. Cholinergic axons project to heterotopia. a Low magnification of the propidium iodide-stained section with visible heterotopion (arrows). b Same section as shown in a with visible ChAT-labeled axons in the heterotopion and ChAT-labeled neurons immediately beneath the heterotopion. c Higher magnification of the section shown in b. d Example of ChAT-labeled neurons and axons present in heterotopion. All data (a-d) are from primary histological samples from our laboratory and all are from C57BL/6J mice. Scale bars: $\mathbf{a}, \mathbf{b}=200 \mu \mathrm{m} ; \mathbf{c}=66 \mu \mathrm{m} ; \mathbf{d}=50 \mu \mathrm{m}$.
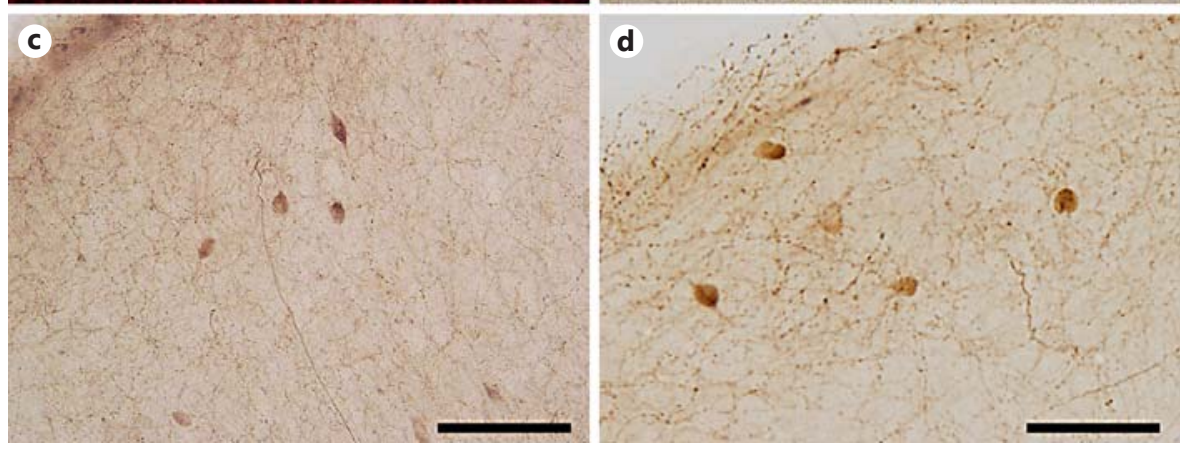

as the presence or location of MLH are not known a priori to tracer injection.

A total of 85 cases found in the MCP were rigorously screened for MLH based on the locations of tracer injections made into regions where MLH are most commonly found, including the frontal, motor, and somatosensory cortices. From this group, 18 cases (21\%) were identified containing MLH. Only 2 cases were found that contained any tracer labeling; however, the labeling present in these cases did indicate that heterotopia send and receive afferent and efferent (respectively) callosal projections. This small number of cases is expected given that the location of heterotopia are not known before tracer injection. Figure 7 contains photomicrographs from a case (SW110210-03A) where the retrograde tracer, cholera toxin $\beta$-subunit (Ctb), was injected unilaterally into the primary motor cortex. As shown in figure $7 \mathrm{a}-\mathrm{d}$ (arrows), a heterotopion was identified contralateral to the Ctb in- 
Fig. 6. Catecholaminergic axons project to heterotopia. a Low magnification of the $\mathrm{TH}$-stained (a) and propidium iodidestained (inset) section with visible heterotopion (arrows). Arrowhead points to the unstained region corresponding to the myelinated axon bundle. b, c High magnification of heterotopion shown in a. d High magnification of the unstained axon bundle region in a demonstrating sparse $\mathrm{TH}$ labeled axons. All data (a-d) are from primary histological samples from our laboratory and all are from C57BL/6J mice. Scale bars: $\mathbf{a}$, inset $=800 \mu \mathrm{m} ; \mathbf{b}=80 \mu \mathrm{m} ; \mathbf{c}, \mathbf{d}=$ $160 \mu \mathrm{m}$.
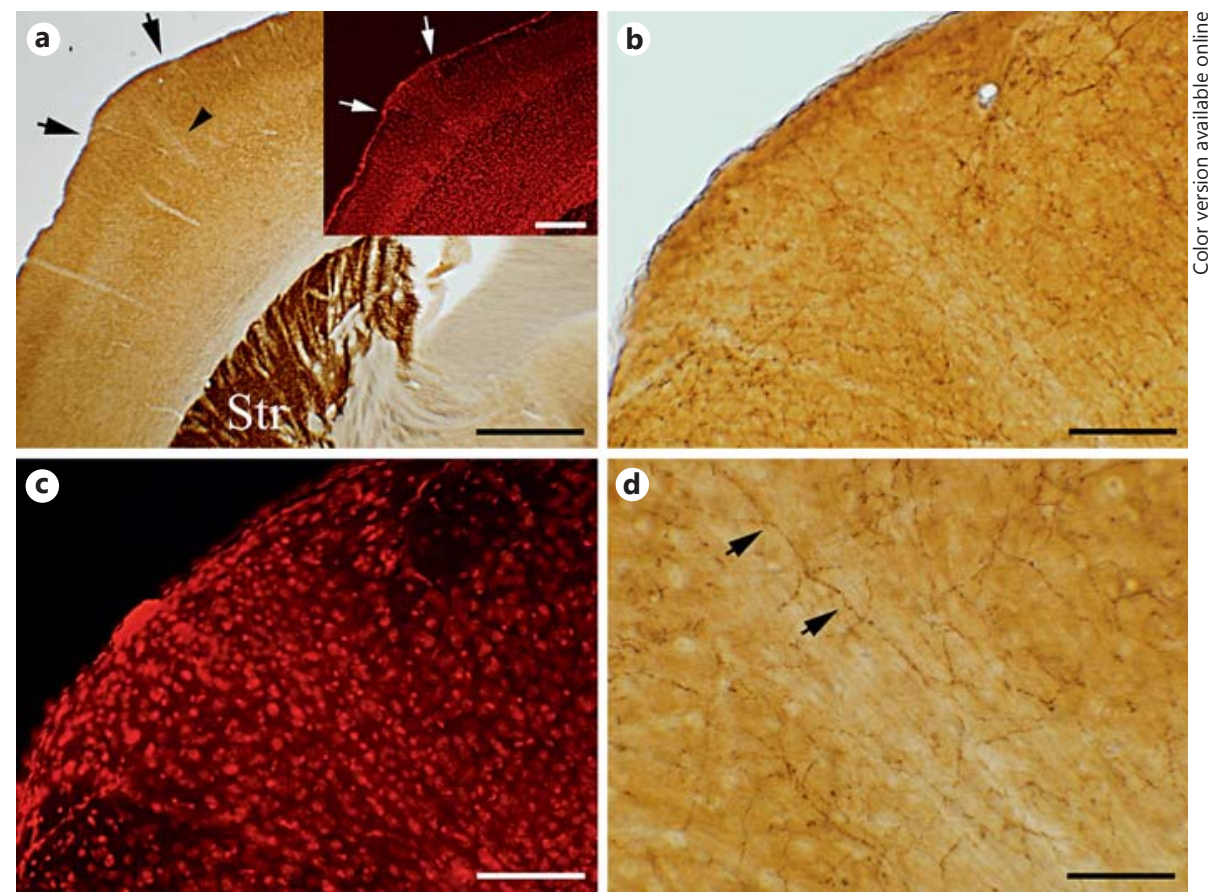

jection site and retrogradely labeled neurons were present in the malformation (fig. $7 \mathrm{~d}$, arrowhead and inset). In this same case, the anterograde tracer, Phaseolus vulgaris leucoagglutinin (PhaL), was injected unilaterally into the same site as Ctb. As shown in figure 7e-h (arrows), anterogradely labeled axons were present in the heterotopion (fig. $7 \mathrm{~h}$, arrowhead and inset).

A total of 380 cases found in the MBAP were rigorously screened for MLH based on the locations of tracer injections made into regions where MLH are most commonly found, including the frontal, motor and somatosensory cortices. From this group, 27 cases (7\%) were identified containing MLH and 11 had labeling in heterotopia, which was indicative of callosal or local innervation into heterotopia. Figure 8 shows 2 representative cases of ipsilateral anterograde labeling in heterotopia. In the first example (fig. 8a-d), a heterotopion (fig. 8a, b, black arrow) can be seen lateral to a biotinylated dextran amine (BDA) injection site (fig. 8a, white arrow) found in the ipsilateral cingulate cortex along the same rostrocaudal plane. Higher magnification of the heterotopion (fig. 8c, d), reveals BDA-labeled axons present within, suggesting that axons from ipsilateral/medial sites innervate the heterotopion. In the second example (fig. $8 \mathrm{e}-\mathrm{i}$ ), a heterotopion (fig. 8e, f, arrow) can be seen ipsilateral and rostral to the injection tracer site (fig. 8g, arrow). Higher magnification of the heterotopion (fig. 8h, i) reveals labeled ax- ons present within, suggesting that axons from ipsilateral/caudal sites innervate the heterotopion.

Figure 8 also shows 2 representative cases of callosal axons in heterotopia. In the first example (fig. $8 j-n$ ), a heterotopion (fig. $8 \mathrm{j}$, $\mathrm{k}$, black arrow) can be seen rostral to a BDA injection site (fig. 81, arrow) found in the contralateral somatosensory cortex at a more caudal position. Higher magnification of the heterotopion (fig. $8 \mathrm{~m}, \mathrm{n}$ ) reveals $B D A-l a b e l e d$ axons present within, suggesting that axons from contralateral/caudal sites innervate the MLH. In the second example (fig. 8o-s), a heterotopion (fig. 8o, $\mathrm{p}$, arrow) can be seen rostral to the tracer injection site (fig. 8q, arrow) found in the contralateral somatosensory cortex at a more caudal position. Higher magnification of the heterotopion (fig. 8r, s) reveals BDA-labeled axons present within, suggesting that axons from contralateral/ caudal sites innervate the MLH.

Together, data from the MCP and MBAP demonstrate that callosal afferent and efferent projections are associated with MLH.

\section{Discussion}

Despite having been associated with dyslexia, epilepsy, cobblestone lissencephaly, polymicrogyria, and Fukuyama muscular dystrophy [1-8], a complete understand- 


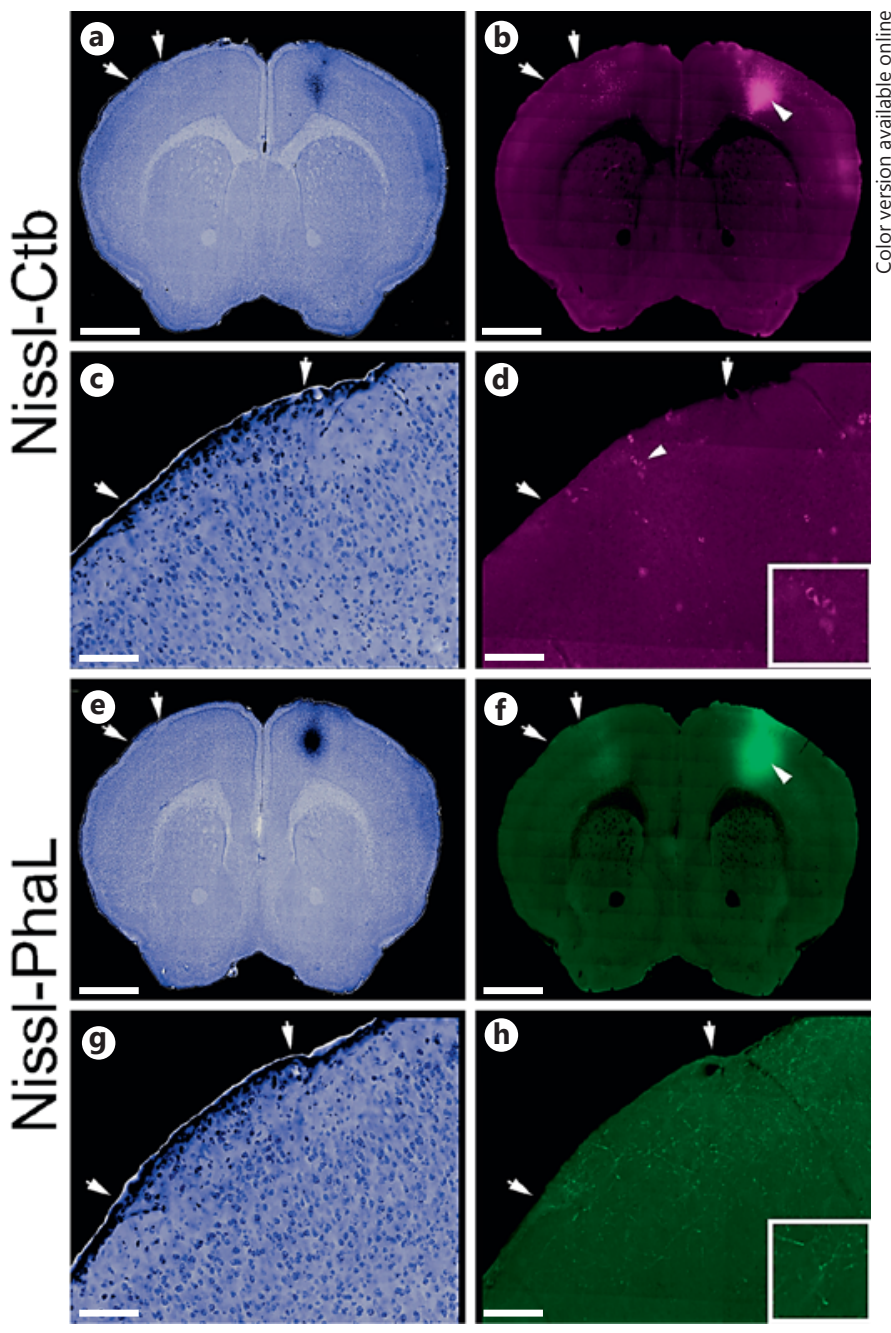

Fig. 7. Data found in the MCP indicate that MLH send and receive contralateral projections. a, b Injection of Ctb into the motor cortex (arrowhead in b) results in retrogradely labeled neurons in the heterotopion found in the contralateral hemisphere (arrows in $\mathbf{a}, \mathbf{b})$. a Nissl-stained adjacent section to that shown in $\mathbf{b}$. c, d High magnification of the heterotopion shown in $\mathbf{a}$ and $\mathbf{b}$, respectively. Arrowhead in $\mathbf{d}$ points to individual labeled neurons. Inset in d shows higher magnification of retrogradely labeled neurons in MLH. e, $\mathbf{f}$ Injection of PhaL into the motor cortex (arrowhead in f) results in anterogradely labeled axons in the heterotopion found in the contralateral hemisphere (arrows in e, f). e Nisslstained adjacent section to that shown in $\mathbf{f} . \mathbf{g}, \mathbf{h}$ High magnification of the heterotopion shown in $\mathbf{e}$ and $\mathbf{f}$, respectively. Inset in $\mathbf{h}$ shows higher magnification of labeled axons. All data $(\mathbf{a}-\mathbf{h})$ are from MCP and all are from C57BL/6J mice. Scale bars: $\mathbf{a}, \mathbf{b}, \mathbf{e ,} \mathbf{f}=$ $1,000 \mu \mathrm{m} ; \mathbf{c}, \mathbf{d}, \mathbf{g}, \mathbf{h}=15 \mu \mathrm{m}$.

ing of the cellular and axonal constituents of MLH is lacking. In the present report we further document the cellular and axonal anatomy of MLH in mice, as a tool toward understanding MLH in humans.

Cells and Circuits of Neocortical

Heterotopia
Using the ABA, we show that excitatory neurons from all neocortical layers are present in MLH, suggesting that neurons born during all periods of corticogenesis are present in heterotopia. These data are consistent with the observation of glutamatergic postsynaptic potentials recorded from neurons in MLH [33]. In addition, we demonstrate that numerous GABAergic neuron subtypes are present in MLH, including those born in the caudal (Vip) and medial (Pvalb) ganglionic eminence as well as those making somatic and dendritic inhibitory synapses. These data are consistent with the observation of GABAergic postsynaptic potentials recorded from neurons in $\mathrm{MLH}$ [33]. Taken together, these data indicate that there exists a diverse complement of neurons in MLH and suggest that these neurons may participate in a synaptic network that contributes to the cortical dysfunction manifested by patients with MLH. Consistent with this hypothesis, mice with MLH have impaired learning of spatial and nonspatial memory tasks [24-28], sensory processing deficits [29-32] and increased seizure susceptibility [34]. Future studies should be aimed at characterizing the synaptic circuitry and physiological profile of neurons in C57BL/6J mice with MLH, toward gaining a better understanding of how heterotopia cause cortical dysfunction.

Radial glial fibers are disrupted in areas of developing MLH [11]. Surprisingly, an analysis of adult mice with MLH did not reveal significant changes in glial cell distribution or morphology. In particular, neither reactive astrocytes nor activated microglia were identified by GFAP or Ibal immunostaining. These observations were confirmed with data from the ABA as well as in laminin $\beta 2 /$ $\gamma 3$ double-KO mice that exhibit numerous and large MLH throughout most of the neocortex [14]. Consistent with earlier findings of myelinated axons in MLH [12, 13], we identified oligodendrocytes in MLH using immunostaining for Olig2 as well as data from the ABA. Taken together, these data demonstrate that all three subtypes of glia are present in MLH. An important caveat of our findings is that only a limited number of ages/time-points were examined for any given glial cell marker, leaving open the possibility that changes in glial cell number or activity occur in older ages than those examined.

Using immunocytochemistry for neurotransmitterspecific phenotypes, we identified ChAT, 5HTT and THlabeled axons in heterotopia. We propose that cholinergic axons in the MLH likely arise from basal forebrain nuclei $[63,64]$, while it is likely that those expressing 5HTT originate in the median raphe [65]. The catecholaminergic fibers that were present probably arise from noradrenergic neurons in the locus coeruleus $[66,67]$ and dopami- 

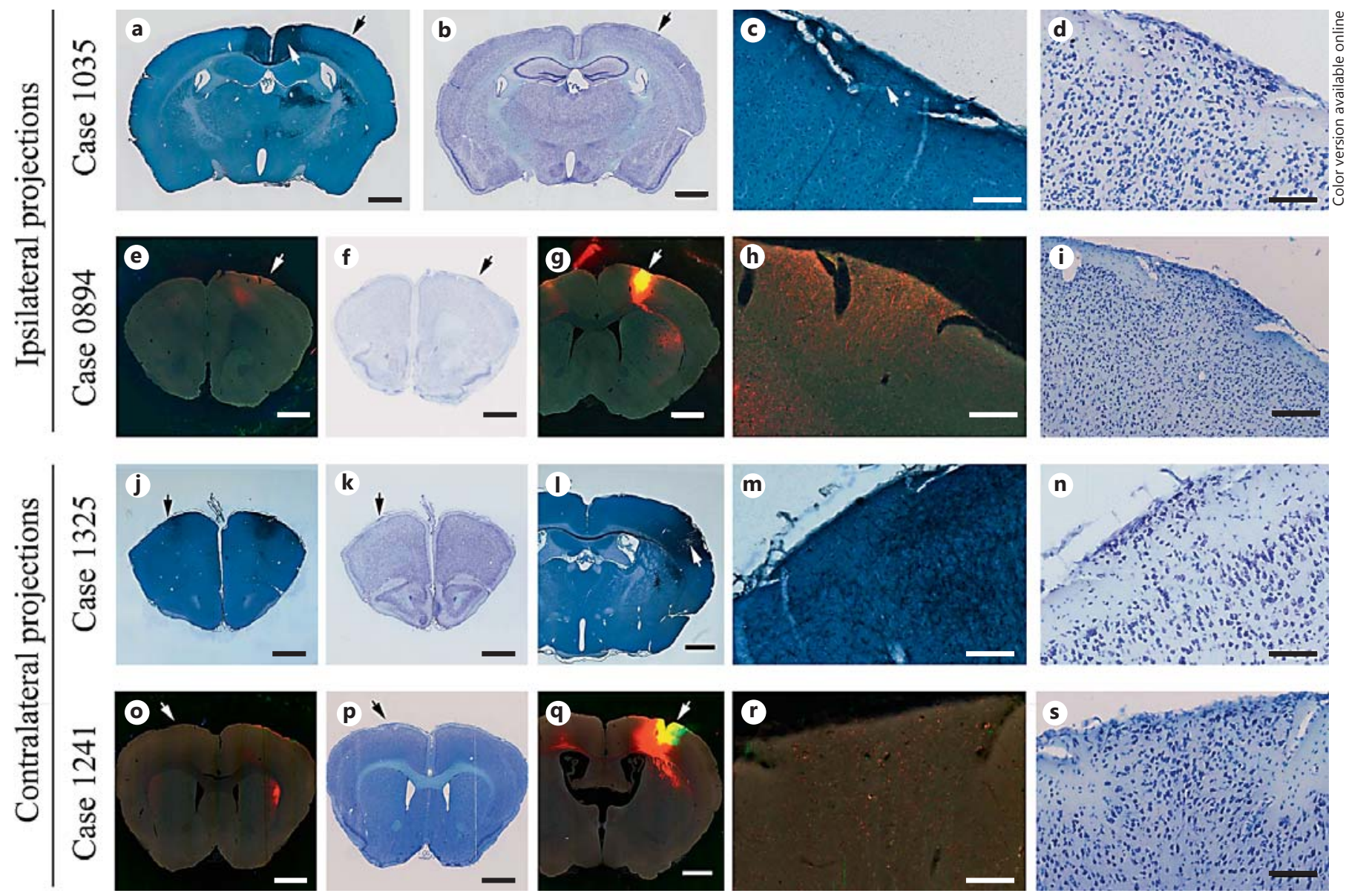

Fig. 8. Data found in the MBAP indicate that MLH receive ipsilateral and contralateral projections. a Injection of BDA into the cingulate cortex (white arrow in a) results in labeled axons in the adjacent heterotopion (black arrow in a). b Nissl-stained adjacent section to that shown in a. c, d High magnification of the heterotopion shown in $\mathbf{a}$ and $\mathbf{b}$, respectively. e, $\mathbf{g}$ The heterotopion in the frontal motor cortex (arrows in e, f) contains anterogradely labeled axons after injection in the ipsilateral motor cortex (arrow in $\mathbf{g}$ ) at a more caudal level. $\mathbf{f}$ Nissl-stained adjacent section to that shown in $\mathbf{e} . \mathbf{h}, \mathbf{i}$ High magnification of the heterotopion shown in $\mathbf{e}$ and $\mathbf{f}$, respectively. j-I The heterotopion in the frontal motor cortex (ar-

nergic neurons of the ventral tegmental area $[68,69]$. Though definitive electron microscopic data confirming synaptic contacts within MLH are lacking, these data suggest that axons from subcortical neuromodulatory centers innervate neurons in MLH.

In the present report, we identify cortical afferent and efferent projections of MLH, which include local ipsilateral afferents, callosal afferents, and callosal efferents. Exactly how these connections participate in the cortical dysfunction associated with heterotopia (learning and memory deficits, increased seizure susceptibility) is not rows in $\mathbf{j}, \mathbf{k}$ ) contains anterogradely labeled axons after injection in the contralateral somatosensory cortex (arrow in I) at a more caudal level. $\mathbf{k}$ Nissl-stained adjacent section to that shown in $\mathbf{j} . \mathbf{m}$, $\mathbf{n}$ High magnification of the heterotopion shown in $\mathbf{j}$ and $\mathbf{k}$, respectively. $\mathbf{0 - q}$ The heterotopion in the motor cortex (arrows in $\mathbf{0}, \mathbf{p}$ ) contains anterogradely labeled axons after injection in the contralateral somatosensory cortex (arrow in q) at a more caudal level. p Nissl-stained adjacent section to that shown in j. r, s High magnification of the heterotopion shown in $\mathbf{o}$ and $\mathbf{p}$, respectively. All data (a-s) are from MBAP and all are from C57BL/6J mice. Scale bars: $\mathbf{a}, \mathbf{b}, \mathbf{e}-\mathbf{g}, \mathbf{j}-\mathbf{I}, \mathbf{o}-\mathbf{q}=1,000 \mu \mathrm{m} ; \mathbf{c}, \mathbf{d}, \mathbf{h}, \mathbf{i}, \mathbf{m}, \mathbf{n}, \mathbf{r}, \mathbf{s}=100 \mu \mathrm{m}$.

known. However, due to the excitatory/glutamatergic profile of these circuits, epileptiform activity initiated by heterotopic neurons could propagate via one or more of these pathways. There are likely to be additional circuitry changes present in the 'normatopic' cortex which remain unidentified but that participate in the cortical dysfunction associated with MLH. Furthermore, an important caveat to our axonal immunohistochemical data and the virtual tracer data is that a limited age range of brains was examined and afferent/efferent connections associated with MLH could change over time. 
We believe that most, if not all, of the molecular markers demonstrated above would be present in most, if not all, heterotopia. First, YFP-labeled neurons were found in $100 \%$ of heterotopia in Thy1-YFP mice with MLH, suggesting that there are always layer $\mathrm{V}$ neurons in heterotopia. Second, we show multiple layer-specific molecular markers (layer II-III, IV, V, VI), which supports our observations in Thy1-YFP mice. In addition, we show 7 different molecular markers for GABAergic neurons which are found in heterotopia. Given the fact that Gad1 is found in all of the interneuron subtypes shown, this would argue strongly for the fact that $100 \%$ of heterotopia will have some complement of GABAergic neurons. We also demonstrate several examples of glial cell markers with largely overlapping expression profiles within a given glial cell type (astrocyte, oligodendrocytes, etc.), lending support to our interpretation of data for layer-specific neurons and GABAergic subtypes in heterotopia. Third, our immunocytochemical studies examining axonal afferents (cholinergic, serotonergic, catecholaminergic) in heterotopia yielded similar staining profiles in multiple brains with heterotopia examined. Fourth, we have previously shown that MLH are associated with myelinated axon bundles across different substrains of C57BL/6 mice and in both males and females [13], suggesting that the axonal constituents described above are also likely to be present in most heterotopia. Taken together, these data suggest that the cellular and axonal constituents of MLH are consistent and that it is likely that each of the given cell types illustrated above would be present in most, if not all, heterotopias.

MLH almost identical to that observed in C57BL/6J mice are found in numerous transgenic and $\mathrm{KO}$ mice. In transgenic mice generated on a C57BL/6J background or backcrossed onto this strain, we believe that MLH formation results from the $\mathrm{C} 57 \mathrm{BL} / 6 \mathrm{~J}$ genotype, as we have shown with Thy1-YFP mice in the present report, and in BXD and AXB recombinant inbred mice, which we demonstrated previously [13]. Unpublished results from an ongoing study using the ABA Transgenic Characterization database (http://connectivity.brain-map.org/transgenic) also indicate that Cre-Lox transgenic mice on a C57BL/6J (or congenic) background exhibit MLH, which is consistent with the finding that Cre-Lox transgenic mice can exhibit malformations of the posterior cerebellum [70].

Although heterotopia can be significantly larger and more prevalent in mutant and $\mathrm{KO}$ mice, we believe that heterotopia in mutant/KO mice share many similarities to MLH seen in C57BL/6J mice. First, the general cytoarchi- tectonic profile of heterotopia in several KOs is strikingly similar, with the characteristic feature of cells in the molecular layer. Second, there is evidence that the cellular constituents of heterotopia in mutant/KO mice are similar to those seen in MLH in C57BL/6J mice. For example, in the following mutant/KO mice: Fak [22], Gpr56 [15], Col3a1 [71], Dag1 [72] and Foxc1 [73], heterotopia were found to contain layer V neurons that express CTIP2 and/ or ER81, which is similar to our findings in C57BL/6J mice. Moreover, heterotopia in Zic1/3 mutants [74] were found to contain GAD-expressing neurons similar to our observations. Third, in NXSMD/EiJ mice, which are a recombinant inbred line derived from NZB/BinJ and SM/J progenitors, heterotopia contains oligodendrocytes, GFAPexpressing astrocytes and several GABAergic neuron subtypes, including PVALB-expressing neurons [75], which is also similar to our observations in C57BL/6J mice. Fourth, preliminary analysis of layer-specific neuronal expression in MLH found in Cre-Lox transgenic mice (ABA Transgenic Characterization database) confirms our observation of Etv1 (P56; ABA 100126208)-expressing cells and Pvalb (P147; ABA 100144576)-expressing cells in heterotopia. Taken together, these data indicate that heterotopia in $\mathrm{KO}$, mutant and transgenic mice share a similar cellular composition to that seen in C57BL/6J heterotopia.

In the present report we describe the cellular and axonal composition of MLH in C57BL/6J mice, placing MLH among the most anatomically well-described neocortical malformations in a rodent model. Nevertheless, to date, little is known regarding the underlying molecular mechanisms that cause heterotopia or exactly how the cells and circuits associated with heterotopia result in cortical dysfunction. This is an important area for future investigation. More broadly, our results demonstrate the importance of careful consideration as to how MLH may affect anatomical, physiological and behavioral studies using C57BL/6J mice. Transgenic and $\mathrm{KO}$ mice generated on a $\mathrm{C} 57 \mathrm{BL} / 6 \mathrm{~J}$ background presenting with a heterotopia phenotype must also be carefully evaluated in light of the known prevalence of MLH in C57BL/6J mice.

References

Dev Neurosci 2014;36:477-489

Galaburda AM, Kemper TL: Cytoarchitectonic abnormalities in developmental dyslexia: a case study. Ann Neurol 1979;6:94-100.

-2 Galaburda AM, Sherman GF, Rosen GD, Aboitiz F, Geschwind N: Developmental dyslexia: four consecutive patients with cortical anomalies. Ann Neurol 1985;18:222-233.

3 Humphreys P, Kaufmann WE, Galaburda AM: Developmental dyslexia in women: neuropathological findings in three patients. Ann Neurol 1990;28:727-738. 
-4 Eriksson SH, Rydenhag B, Uvebrant P, Malmgren K, Nordborg C: Widespread microdysgenesis in therapy-resistant epilepsy a case report on post-mortem findings. Acta Neuropathol 2002;103:74-77.

5 Nordborg C, Eriksson S, Rydenhag B, Uvebrant $\mathrm{P}$, Malmgren K: Microdysgenesis in surgical specimens from patients with epilepsy: occurrence and clinical correlations. J Neurol Neurosurg Psychiatry 1999;67:521524.

6 Olson EC, Walsh CA: Smooth, rough and upside-down neocortical development. Curr Opin Genet Dev 2002;12:320-327.

7 Bahi-Buisson N, Poirier K, Boddaert N, Fallet-Bianco C, Specchio N, et al: GPR56-related bilateral frontoparietal polymicrogyria: further evidence for an overlap with the cobblestone complex. Brain 2010;133:31943209.

8 Yamamoto T, Toyoda C, Kobayashi M, Kondo E, Saito K, et al: Pial-glial barrier abnormalities in fetuses with Fukuyama congenital muscular dystrophy. Brain Dev 1997;19:35-42.

-9 Sherman GF, Galaburda AM, Geschwind N: Cortical anomalies in brains of New Zealand mice: a neuropathologic model of dyslexia? Proc Natl Acad Sci USA 1985;82:8072-8074.

-10 Sherman GF, Galaburda AM, Behan PO, Rosen GD: Neuroanatomical anomalies in autoimmune mice. Acta Neuropathol 1987; 74:239-242.

-11 Sherman GF, Holmes LB: Cerebrocortical microdysgenesis is enhanced in c57BL/6J mice exposed in utero to acetazolamide. Teratology 1999;60:137-142.

$\checkmark 12$ Ramos RL, Smith PT, DeCola C, Tam D, Corzo $\mathrm{O}$, et al: Cytoarchitecture and transcriptional profiles of neocortical malformations in inbred mice. Cereb Cortex 2008;18:26142628.

-13 Lipoff DM, Bhambri A, Fokas GJ, Sharma S, Gabel LA, et al: Neocortical molecular layer heterotopia in substrains of C57BL/6 and C57BL/10 mice. Brain Res 2011;1391:36-43.

-14 Radner S, Banos C, Bachay G, Li YN, Hunter $\mathrm{DD}$, et al: $\beta 2$ and $\gamma 3$ laminins are critical cortical basement membrane components: ablation of Lamb2 and Lamc3 genes disrupts cortical lamination and produces dysplasia. Dev Neurobiol 2013;73:209-229.

15 Li S, Jin Z, Koirala S, Bu L, Xu L, et al: GPR56 regulates pial basement membrane integrity and cortical lamination. J Neurosci 2008;28 5817-5826.

16 Iguchi T, Sakata K, Yoshizaki K, Tago K, Mizuno N, et al: Orphan $G$ protein-coupled receptor GPR56 regulates neural progenitor cell migration via a $\mathrm{G}$ alpha $12 / 13$ and Rho pathway. J Biol Chem 2008;283:14469-14478.

17 Niewmierzycka A, Mills J, St-Arnaud R, Dedhar S, Reichardt LF: Integrin-linked kinase deletion from mouse cortex results in cortical lamination defects resembling cobblestone lissencephaly. J Neurosci 2005;25:7022-7031.
8 Haubst N, Georges-Labouesse E, De Arcangelis A, Mayer U, Götz M: Basement membrane attachment is dispensable for radial glial cell fate and for proliferation, but affects positioning of neuronal subtypes. Development 2006;133:3245-3254.

19 Halfter W, Dong S, Yip Y-P, Willem M, Mayer U: A critical function of the pial basement membrane in cortical histogenesis. J Neurosci 2002;22:6029-6040.

20 Michele DE, Barresi R, Kanagawa M, Saito F, Cohn RD, et al: Post-translational disruption of dystroglycan-ligand interactions in congenital muscular dystrophies. Nature 2002; 418:417-422.

21 Moore SA, Saito F, Chen J, Michele DE, Henry $\mathrm{MD}$, et al: Deletion of brain dystroglycan recapitulates aspects of congenital muscular dystrophy. Nature 2002;418:422-425.

22 Beggs HE, Schahin-Reed D, Zang K, Goebbels $S$, Nave KA, et al: FAK deficiency in cells contributing to the basal lamina results in cortical abnormalities resembling congenital muscular dystrophies. Neuron 2003;40:501-514.

$23 \mathrm{Hu} \mathrm{H}$, Yang Y, Eade A, Xiong Y, Qi Y: Breaches of the pial basement membrane and disappearance of the glia limitans during development underlie the cortical lamination defect in the mouse model of muscle-eye-brain disease. J Comp Neurol 2007;502:168-183.

24 Boehm GW, Sherman GF, Hoplight BJ, Hyde LA, Waters NS, et al: Learning and memory in the autoimmune BXSB mouse: effects of neocortical ectopias and environmental enrichment. Brain Res 1996;726:11-22.

25 Hoplight BJ, Sherman GF, Hyde LA, Denenberg VH: Effects of neocortical ectopias and environmental enrichment on Hebb-Williams maze learning in BXSB mice. Neurobiol Learn Mem 2001;76:33-45.

26 Hyde LA, Sherman GF, Hoplight BJ, Denenberg VH: Working memory deficits in BXSB mice with neocortical ectopias. Physiol Behav 2000;70:1-5.

27 Hyde LA, Hoplight BJ, Harding S, Sherman GF, Mobraaten LE, et al: Effects of ectopias and their cortical location on several measures of learning in BXSB mice. Dev Psychobiol 2001;39:286-300.

28 Waters NS, Sherman GF, Galaburda AM, Denenberg VH: Effects of cortical ectopias on spatial delayed-matching-to-sample performance in BXSB mice. Behav Brain Res 1997; 84:23-29.

29 Clark MG, Sherman GF, Bimonte HA, Fitch RH: Perceptual auditory gap detection deficits in male BXSB mice with cerebrocortical ectopias. Neuroreport 2000;11:693-696.

30 Peiffer AM, Dunleavy CK, Frenkel M, Gabel LA, LoTurco JJ, et al: Impaired detection of variable duration embedded tones in ectopic NZB/BINJ mice. Neuroreport 2001;12:28752879.

31 Peiffer AM, Rosen GD, Fitch RH: Sex differences in rapid auditory processing deficits in ectopic BXSB/MpJ mice. Neuroreport 2002; 13:2277-2280.
32 Frenkel M, Sherman GF, Bashan KA, Galaburda AM, LoTurco JJ: Neocortical ectopias are associated with attenuated neurophysiological responses to rapidly changing auditory stimuli. Neuroreport 2000;11:575-579.

-33 Gabel LA, LoTurco JJ: Electrophysiological and morphological characterization of neurons within neocortical ectopias. J Neurophysiol 2001;85:495-505.

34 Gabel LA, Manglani M, Ibanez N, Roberts J, Ramos RL, et al: Differential seizure response in two models of cortical heterotopia. Brain Res 2013;1494:84-90.

- 35 Feng G, Mellor RH, Bernstein M, Keller-Peck C, Nguyen QT, et al: Imaging neuronal subsets in transgenic mice expressing multiple spectral variants of GFP. Neuron 2000;28:4151.

-36 Mangaru Z, Salem E, Sherman M, Van Dine SE, Bhambri A, et al: Neuronal migration defect of the developing cerebellar vermis in substrains of C57BL/6 mice: cytoarchitecture and prevalence of molecular layer heterotopia. Dev Neurosci 2013;35:28-39.

37 Ramos RL, Tam DM, Brumberg JC: Physiology and morphology of callosal projection neurons in mouse. Neuroscience 2008; 153 : 654-663

38 Van Dine SE, Salem E, Patel DB, George E, Ramos RL: Axonal anatomy of molecular layer heterotopia of the cerebellar vermis. J Chem Neuroanat 2013;47:90-95.

39 Steger R, Ramos RL, Cao R, Dominici J, Brumberg JC, et al: Physiology and morphology of inverted pyramidal neurons in the rodent neocortex. Neuroscience 2013;248:165179.

40 Lein ES, Hawrylycz MJ, Ao N, Ayres M, Bensinger A, et al: Genome-wide atlas of gene expression in the adult mouse brain. Nature 2007;445:168-176.

41 Arlotta P, Molyneaux BJ, Chen J, Inoue J, Kominami R, et al: Neuronal subtype-specific genes that control corticospinal motor neuron development in vivo. Neuron 2005; 45 : 207-221.

42 Molyneaux BJ, Arlotta P, Hirata T, Hibi M, Macklis JD: Fezl is required for the birth and specification of corticospinal motor neurons. Neuron 2005;47:817-831

43 Molyneaux BJ, Arlotta P, Menezes JRL, Macklis JD: Neuronal subtype specification in the cerebral cortex. Nat Rev Neurosci 2007;8: 427-437.

44 Molyneaux BJ, Arlotta P, Fame RM, MacDonald JL, MacQuarrie KL, et al: Novel subtype-specific genes identify distinct subpopulations of callosal projection neurons. J Neurosci 2009;29:12343-12354.

45 Hevner RF, Daza RAM, Rubenstein JLR, Stunnenberg H, Olavarria JF, et al: Beyond laminar fate: toward a molecular classification of cortical projection/pyramidal neurons. Dev Neurosci 2003;25:139-151. 
-46 DeFelipe J, López-Cruz PL, Benavides-Piccione $\mathrm{R}$, Bielza C, Larrañaga $\mathrm{P}$, et al: New insights into the classification and nomenclature of cortical GABAergic interneurons. Nat Rev Neurosci 2013;14:202-216.

-47 Angevine JB, Sidman RL: Autoradiographic study of cell migration during histogenesis of cerebral cortex in the mouse. Nature 1961; 192:766-768.

48 Rakic P: Neurons in rhesus monkey visual cortex: systematic relation between time of origin and eventual disposition. Science 1974; 183:425-427.

-49 Gupta A, Tsai L-H, Wynshaw-Boris A: Life is a journey: a genetic look at neocortical development. Nat Rev Genet 2002;3:342-355.

-50 Porrero C, Rubio-Garrido P, Avendaño C, Clascá F: Mapping of fluorescent protein-expressing neurons and axon pathways in adult and developing Thy1-eYFP-H transgenic mice. Brain Res 2010;1345:59-72.

51 Gelman DM, Marín O: Generation of interneuron diversity in the mouse cerebral cortex. Eur J Neurosci 2010;31:2136-2141.

52 Rudy B, Fishell G, Lee S, Hjerling-Leffler J: Three groups of interneurons account for nearly $100 \%$ of neocortical GABAergic neurons. Dev Neurobiol 2011;71:45-61.

-53 Kawaguchi Y, Kubota Y: GABAergic cell subtypes and their synaptic connections in rat frontal cortex. Cereb Cortex 1997;7:476-486.

-54 Belluardo N, Mudò G, Trovato-Salinaro A, Le Gurun S, Charollais A, et al: Expression of connexin36 in the adult and developing rat brain. Brain Res 2000;865:121-138.

55 Fukuda T, Kosaka T: The dual network of GABAergic interneurons linked by both chemical and electrical synapses: a possible infrastructure of the cerebral cortex. Neurosci Res 2000;38:123-130.

-56 Staiger JF, Freund TF, Zilles K: Interneurons immunoreactive for vasoactive intestinal polypeptide (VIP) are extensively innervated by parvalbumin-containing boutons in rat primary somatosensory cortex. Eur J Neurosci 1997;9:2259-2268.
57 Sohn J, Hioki H, Okamoto S, Kaneko T: Preprodynorphin-expressing neurons constitute a large subgroup of somatostatin-expressing GABAergic interneurons in the mouse neocortex. J Comp Neurol 2013;522:1506-1526.

58 Zhou Q, Wang S, Anderson DJ: Identification of a novel family of oligodendrocyte lineagespecific basic helix-loop-helix transcription factors. Neuron 2000;25:331-343.

59 Lu QR, Yuk D, Alberta JA, Zhu Z, Pawlitzky I, et al: Sonic hedgehog-regulated oligodendrocyte lineage genes encoding bHLH proteins in the mammalian central nervous system. Neuron 2000;25:317-329.

60 Barrera K, Chu P, Abramowitz J, Steger R, Ramos RL, et al: Organization of myelin in the mouse somatosensory barrel cortex and the effects of sensory deprivation. Dev Neurobiol 2013;73:297-314

61 Imai Y, Ibata I, Ito D, Ohsawa K, Kohsaka S: A novel gene ibal in the major histocompatibility complex class III region encoding an EF hand protein expressed in a monocytic lineage. Biochem Biophys Res Commun 1996; 224:855-862

62 Ito D, Imai Y, Ohsawa K, Nakajima K, Fukuuchi Y, et al: Microglia-specific localisation of a novel calcium binding protein, Iba1. Mol Brain Res 1998;57:1-9.

63 Bigl V, Woolf NJ, Butcher LL: Cholinergic projections from the basal forebrain to frontal, parietal, temporal, occipital, and cingulate cortices: a combined fluorescent tracer and acetylcholinesterase analysis. Brain Res Bull 1982;8:727-749.

64 Mesulam M, Mufson E, Levey A, Wainer B: Cholinergic innervation of cortex by the basal forebrain: cytochemistry and cortical connections of the septal area, diagonal band nuclei, nucleus basalis (substantia innominata), and hypothalamus in the rhesus monkey. J Comp Neurol 1983;214:170-197.

65 Waterhouse BD, Mihailoff GA, Baack JC, Woodward DJ: Topographical distribution of dorsal and median raphe neurons projecting to motor, sensorimotor, and visual cortical areas in the rat. J Comp Neurol 1986;249:460$476,478-481$.
66 Grzanna R, Fritschy JM: Efferent projections of different subpopulations of central noradrenaline neurons. Prog Brain Res 1991;88: 89-101.

67 Loughlin S, Foote S, Fallon J: Locus coeruleus projections to cortex: topography, morphology and collateralization. Brain Res Bull 1982; 9:287-294.

68 Berger B, Gaspar P, Verney C: Dopaminergic innervation of the cerebral cortex: unexpected differences between rodents and primates. Trends Neurosci 1991;14:21-27.

69 Foote S, Morrison J: Development of the noradrenergic, serotonergic, and dopaminergic innervation of neocortex. Curr Top Dev Biol 1987;391-423.

70 Ramos RL, Van Dine SE, George E, Patel D, Hoplight BJ, et al: Molecular layer heterotopia of the cerebellar vermis in mutant and transgenic mouse models on a C57BL/6 background. Brain Res Bull 2013;97:63-68.

71 Jeong S-J, Li S, Luo R, Strokes N, Piao X: Loss of Col3a1, the gene for Ehlers-Danlos syndrome type IV, results in neocortical dyslamination. PLoS One 2012;7:e29767.

72 Myshrall TD, Moore SA, Ostendorf AP, Satz JS, Kowalczyk T, et al: Dystroglycan on radial glia end feet is required for pial basement membrane integrity and columnar organization of the developing cerebral cortex. J Neuropathol Exp Neurol 2012;71:1047-1063.

73 Hecht JH, Siegenthaler JA, Patterson KP, Pleasure SJ: Primary cellular meningeal defects cause neocortical dysplasia and dyslamination. Ann Neurol 2010;68:454-464.

74 Inoue T, Ogawa M, Mikoshiba K, Aruga J: Zic deficiency in the cortical marginal zone and meninges results in cortical lamination defects resembling those in type II lissencephaly. J Neurosci 2008;28:4712-4725.

75 Gabel LA: Layer I neocortical ectopia: cellular organization and local cortical circuitry. Brain Res 2011;1381:148-158. 